Historia

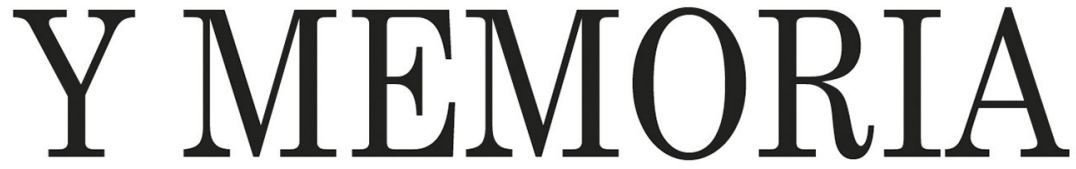

ISSN: 2027-5137 Julio - Diciembre, Año 2016 - Tunja, Colombia

Los tratados de práctica notarial en las bibliotecas de escribanos neogranadinos del siglo XVIII

Alfonso Rubio Hernández Páginas: 19 - 46 DOI: http://dx.doi.org/10.19053/20275137.5198

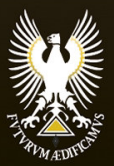




\title{
Los tratados de práctica notarial en las bibliotecas de escribanos neogranadinos del siglo XVIII
}

\author{
Alfonso Rubio Hernández ${ }^{1}$ \\ Universidad del Valle - Colombia
}

Recepción: 20/10/2015

Evaluación: 14/02/2016

Aprobación: 22/02/2016

Artículo de Investigación e Innovación.

DOI: http://dx.doi.org/10.19053/20275137.5198

\section{Resumen}

Entre las bibliotecas particulares de escribanos numerarios y de cabildo que ejercieron durante el siglo XVIII en el Nuevo Reino de Granada, constatamos la presencia de formularios, tratados o manuales prácticos que se inscribieron en la tradición europea de la literatura jurídica de los "ars notariae" y sirvieron para ejercer un oficio fundamental para el desarrollo social y económico de las ciudades americanas, un oficio escasamente estudiado por la historiografía colombiana. Para ello analizamos los Inventarios Post Mortem de Jacobo Facio Lince, Mariano Bueno, Juan Andrés Sandoval y Joaquín Sánchez de la Flor, escribanos que ejercieron su oficio en las

1 Profesor del Departamento de Historia de la Facultad de Humanidades de la Universidad del Valle (Santiago de Cali. Colombia). Licenciado en Filología Hispánica por la Universidad de Zaragoza (España) y Doctor por la misma en el Programa Sistemas de Información y Documentación del Departamento de Ciencias de la Documentación e Historia de la Ciencia. Miembro del Grupo de Investigación NaciónCultura-Memoria. Áreas de especialización: Cultura escrita, Archivística, Paleografía, Diplomática. Publicaciones recientes: La escritura del archivo. Recurso simbólico y poder práctico en el Nuevo Reino de Granada. Santiago de Cali: Universidad del Valle/Facultad de Humanidades/Departamento de Historia, 2014. ISBN: 978-958765-096-9. Los escribanos de la Villa de Medellín, 1675-1819. La representación de un oficio en la escritura de su archivo. Medellín: Editorial Universidad de Antioquia, 2015. ISBN: 978-958-714-624-0. Correo electrónico: alfonso.rubio@correounivalle. edu.co 
ciudades de Medellín, Cartago y Popayán. Los registros de sus bibliotecas particulares nos permiten caracterizarlas para centrarnos luego en la descripción individual de los tratados notariales identificados y su circulación en Indias.

Palabras clave: bibliotecas particulares, escribanos del número y de cabildo, Nuevo Reino de Granada, siglo XVIII, tratados de práctica notarial.

\section{Notarial Practice Treatises in the Libraries of XVIII c. Neogranadino Scribes}

\section{Abstract}

Among the personal libraries of numerary and cabildo scribes during the XVIII c. in the New Kingdom of Granada, we find the presence of forms, treatises or practical manuals inscribed in the tradition of european juridicial "ars notariae" literature, which exercised a fundamental function in the social and economic development of American cities; this task that has been scarcely studied by Colombian historiography. This study analyzes the Post Mortem Inventaries of the scribes Jacobo Facio Lince, Mariano Bueno, Juan Andrés Sandoval and Joaquín Sánchez de la Flor, who exercized their practice in the cities of Medellín, Cartago and Popayán. After a characterization of the personal library archives of these scribes, this study focuses on the individual description of the notarial treatises found, and their circulation in the Indies.

Key Words: personal libraries, numerary and cabildo scribes, New Kingdom of Granada, XVIII century, notarial practice treatises

\section{Les traités de pratique notariale dans les bibliothèques de notaires néogrenadins au XVIII ${ }^{\mathrm{e}}$ siècle}

\section{Résumé}

Les bibliothèques des notaires ayant exercé pendant le $\mathrm{XVIII}^{\mathrm{e}}$ siècle en Nouvelle-Grenade, révèlent l'existence 
des formulaires, des traités ou des manuels qui appartient à la tradition européenne de la littérature juridique des " ars notariae ". Ces textes leur ont permis d'exercer un office fondamental dans les villes américaines, qui a été paradoxalement très peu étudié par l'historiographie colombienne. Afin de combler ce vide, nous analysons les inventaires post mortem de Jacobo Facio Lince, Bon Mariano, Juan Andrés Sandoval et Joaquin Sánchez de la Flor, notaires dans les villes de Medellín, Cartago et Popayán. D’abord nous nous occuperons de caractériser ces bibliothèques privées et ensuite nous ferons une description individuelle des traités notariaux identifiés et nous montrerons leur circulation dans les Indes.

Mots-clés: bibliothèques privées, notaires, Nouveau Royaume de Grenade, XVIII siècle, traités de pratique notariale.

\section{Introducción}

Mediante la escritura, los escribanos de cabildo fijaban primero y custodiaban después las decisiones tomadas por los cabildantes y los actos administrativos a que estas daban lugar. Receptores de documentos de distintas instituciones, productores de actas capitulares y de una muy variada tipología documental que el Cabildo, en el ejercicio de sus funciones, estaba obligado a elaborar; y conservadores de la memoria que con el paso del tiempo iba acumulando el archivo de la ciudad, los escribanos se convirtieron en mediadores entre el Cabildo, como institución gobernante de la ciudad, y los habitantes o pobladores que, como sujetos gobernados, desarrollaban una vida pública y privada en su lugar de residencia.

La figura del escribano de cabildo fue esencial en el desarrollo económico y social de las ciudades fundadas en territorio americano. Si nos detenemos en la Villa de Medellín del Nuevo Reino de Granada, siendo esta un importante centro comercial minero, hasta fines del siglo XVIII la mayoría de sus escribanos de cabildo fueron, además, de "minas y registros", cuya denominación los capacitaba también para 
realizar funciones de carácter hacendístico y de control de la explotación y fundición de metales preciosos.

La Villa de Medellín no contó con escribano del número hasta el año de 1764. Desde su fundación en 1675 hasta entonces transcurrieron noventa años en los que el escribano del concejo lo fue también del número de la ciudad. Durante ese mismo periodo, la falta de escribanos de cabildo nombrados oficialmente fue suplida por los escribanos salientes o por los escribanos entrantes que actuaban como oficiales de pluma. A partir de la creación de las escribanías numerarias, los periodos de ausencia en la escribanía del cabildo son suplidos por los escribanos del número que actuaban como interinos en el cabildo. Estas circunstancias, habituales también en otras ciudades, hicieron que las competencias de una y otra escribanía se confundieran con frecuencia. Durante el periodo colonial que va desde 1675 hasta el año de 1819, cuando en el mes de agosto, el Cabildo proclama la Independencia de la Corona española, del total de los 16 escribanos que ejercieron funciones en el Cabildo de la Villa, 11 fueron escribanos de cabildo y 5 fueron escribanos numerarios.

Ambas escribanías (la del cabildo y la numeraria) influyeron decisivamente en la burocratización de la vida cotidiana de las ciudades americanas y, desde su posición privilegiada, los escribanos, investidos de una "fe pública" que emanaba del rey, fueron custodios del archivo de la ciudad y de los archivos notariales. El escribano del número es el escribano real que solo puede ejercer sus funciones en su jurisdicción asignada. Ejercen su oficio con exclusión de otros y se llaman "numerarios" por ser fijo y determinado el número de los que hay en cada lugar. Estaban capacitados para dar su fe pública en dos ámbitos: el judicial y el extrajudicial y, en ambas esferas, su competencia era muy amplia. Con la fe pública judicial se caracterizaría la actuación de los escribanos relacionados con los actos y determinaciones de los jueces. Dado que su actuación se reducía al ámbito local, su función se centraba en determinadas actuaciones de la justicia capitular, sustituyendo al de Cabildo por su ausencia o por imposibilidad accidental del mismo, y sobre todo, 
cuando se trataba de asuntos judiciales donde intervenían los Corregidores y Alcaldes mayores, donde autenticaban todos los actos y documentos de los procesos que ante ellos debían pasar. A través de la fe pública extrajudicial, el escribano del número podía autorizar las escrituras que contuvieran negocios y contratos celebrados entre particulares ${ }^{2}$.

Clasificadas en dos principales grupos profesionales las escribanías del antiguo régimen, a un primer grupo pertenecerían los "escribanos públicos de número" (con un territorio asignado) y los "escribanos reales" (sin designación de territorio), considerados ambos como los antecesores de los notarios actuales. Al segundo grupo se adscribieron los "escribanos de cámara y gobierno", "de cabildo", "de provincia", "de visita y de la audiencia (los escribanos receptores)", que fueron concebidos como una especie de secretarios que colaboraban en los procesos judiciales y apoyaban a los funcionarios del gobierno en sus labores administrativas ${ }^{3}$. El escribano de cabildo, en definitiva, sería el antecesor del secretario actual en los municipios.

Aunque esta separación está contemplada en la legislación y en el ordenamiento jurídico, fue frecuente encontrar, utilizando la terminología actual, a escribanos funcionando tanto de secretarios de órganos de gobierno como de secretarios de cuerpos judiciales y de notarios. Esta confusión, que no era solamente funcional, sino también personal e institucional, era conocida e incluso fomentada por las instituciones. La división teórica de las funciones no fue reclamada por las autoridades ni tampoco respetada por los escribanos.

Así como el escribano del número podía sustituir al del cabildo, fue habitual que en Indias el escribano del concejo

2 María de los Ángeles Guajardo-Fajardo Carmona, Escribanos en Indias durante la primera mitad del siglo XVI. [Tomos I] (Madrid: Colegios Notariales de España, 1995), 148 y 158. Una relación detallada de funciones específicas y diferenciadas entre el escribano del concejo y el escribano del número, en pp. 137-221.

3 Tamar Herzog, Mediación, archivos y ejercicio. Los escribanos de Quito (siglo XVII). (Frankfurt: Vittorio Klostermann, 1996), 9. 
lo fuera también del número de la ciudad y por lo general se hacía muy difícil delimitar las funciones que el escribano de la ciudad (muchas veces uno solo, sobre todo en el momento de las fundaciones de poblaciones) desempeñaba como escribano del Cabildo o como escribano del Número de la misma.

Las competencias de una y otra escribanía, aun con funciones específicamente marcadas, se confundían con frecuencia, pero ambas estaban sujetas al ejercicio cotidiano de la escritura. Son estos dos tipos de escribanías, representadas por individuos concretos que ejercieron con el título de escribano del número o escribano de cabildo, las que tomamos aquí para verificar una práctica escrituraria que hacía uso de una vieja tradición europea, una tradición que en España se remonta al siglo $\mathrm{X}$, pues desde entonces hay noticias en este país del uso de colecciones de fórmulas llamadas "formularios" útiles en la redacción documental, con fines didácticos para quienes se interesaban por el arte notarial, o con fines de apoyo para quienes ya ejercían como escribanos ${ }^{4}$.

Son escasos los estudios generales en el ámbito latinoamericano y mucho menores los que específicamente se dedican a los formularios notariales desde las bibliotecas particulares de quienes más interesados estaban en poder hacer uso de ellos: los escribanos. En el panorama que atiende al Nuevo Reino de Granada, los estudios sobre los diferentes tipos de escribanía existentes, son todavía incipientes ${ }^{5}$. De acuerdo a nuestros propósitos, los casos de los escribanos que estudiamos (Jacobo Facio Lince, en Medellín; Mariano Bueno, en Cartago; y en la ciudad de Popayán Juan Andrés Sandoval y Joaquín Sánchez de la Flor), todos ellos ejerciendo durante el siglo XVIII, permiten constatar la presencia de

4 Francisco Icaza Dufour, "Nicolás de Yrolo Calar y su obra». Cuadernos del Instituto de Investigaciones Jurídicas. Literatura histórico-jurídica mexicana, $\mathrm{n}^{\circ} 4$ (1987): 23.

5 Un panorama general historiográfico comentado puede verse en Alfonso Rubio, Los escribanos de la Villa de Medellín, 1675-1819. La representación de un oficio en la escritura de su archivo (Medellín: Universidad de Antioquia, 2015), xxii-xxv. Véase también Kathryn Burns, Into the Archive: Writing and Power in Colonial Peru (Durham: Dake University Press, 2010). 
formularios, tratados o manuales prácticos que sirvieron para ejercer la práctica escribanil creando documentos de aplicación del derecho, documentos relacionados con la vida jurídica, entre los cuales ocuparon un lugar relevante los documentos notariales producidos por escribanos numerarios y los documentos judiciales donde intervenían los alcaldes con funciones judiciales junto a sus necesarios escribanos de cabildo.

La cuestión de conocer, clasificar y delimitar el campo de lo impreso, específicamente, en este caso, el de la literatura notarial, está relacionada con la forma de abordarla según características y matizaciones teóricas y metodológicas frecuentemente expuestas por los estudios históricos de la cultura escrita. Los Inventarios Post Mortem (IPM) que tratamos consignan un arco cronológico que va de 1765 a 1808; por tanto, nos situamos ante un ejercicio escribanil que en tres significativas ciudades neogranadinas como fueron Medellín, Popayán y Cartago, se centra en la segunda mitad del siglo XVIII.

Las clasificaciones, las cantidades resultantes de los IPM, importan para poner en relación los límites numéricos con las características que permitan elaborar adecuadamente análisis, a veces, habitualmente por la escasez de fuentes, inevitablemente generales. Claro que no se nos olvidan otros problemas metodológicos y conceptuales, que ya hemos expuesto en otras ocasiones, a la hora de abordar la historia del libro, de las bibliotecas o de la lectura a través de los IPM. No podemos extraer idénticas evaluaciones de los inventarios de los libros reunidos por distintos individuos que poseen, según sus trayectorias vitales y profesionales, una significación social o cultural y una personalidad lectora distintas. Precisamente por ello no es objetivo aquí detenernos en variantes sociológicas relacionadas con la posesión de más o menos, de unos u otros libros, ni interpretar la variedad de temas o la variedad de títulos. Nos centramos, sin excluir tangencialmente esos aspectos y de manera parcial, en los tratados de práctica notarial para constatar su presencia y su funcionalidad, que desde una lectura informativa y práctica, 
fueron auxilio del ejercicio profesional de los escribanos. Las coincidencias en la posesión de estos formularios o manuales por parte de los escribanos, que generalmente conformaron bibliotecas de escasos títulos, son un referente para conceder a ellas un carácter práctico-laboral y ofrecer algunos rasgos generales.

Formularios que aparecen en bibliotecas del siglo XVIII, cuyas primeras ediciones, en algunos casos, y cuya tradición de ser enviados a través de la Carrera de Indias, procedían de mucho tiempo atrás, por ello nos detenemos también en algunas significativas obras que editadas en el siglo XVI y XVII se recibían en Indias. Al lado de la literatura notarial, la literatura jurídica podía servir también de apoyo a las funciones escribaniles, de ahí que nos hayamos dedicado exclusivamente a extraer la relación de ambos tipos de obras, y no otras, en función del oficio que ejercieron y no de sus gustos o intereses personales por la adquisición de otras temáticas.

\section{Libros y manuales en la práctica escrituraria de los escribanos}

El aprendizaje del escribano se conseguía con el ejercicio del propio oficio. Trabajaban como escribientes o como "oficiales menores o mayores" apoyando las tareas del escribano titular y aprendiendo con la práctica las reglas propias del oficio, las fórmulas documentales y la legislación a la cual acudir. La "idoneidad" para hacerse con el cargo debía ser demostrada mediante un examen, donde habitualmente se empleó la fórmula de hacer "preguntas y repreguntas" al aspirante. El día 30 de julio de 1800, el alcalde de primer voto de la ciudad de Santiago de Cali, con el asesoramiento de Joaquín Caicedo y Cuero, abogado de las Reales Audiencias, hacen comparecer al futuro escribano del número Antonio de Velasco. A la manera de manuales prácticos para escribanos y posteriores compilaciones de los mismos, Antonio de Velasco ${ }^{6}$

$6 \quad$ Manuales notariales editados en la época como el Examen y práctica de escribanos (Primera edición, Madrid, 1641), de Diego González de Villarroel, estaban dirigidos a aspirantes a escribano con intenciones de examinarse. El Compendio de contratos 
[...] fue preguntado, y repreguntado por dicho letrado de muchos y diversos articulos, en punto de actuacion testamentos, tutorías, compromisos, y diversidad de ynstrumentos y escripturas publicas y haviendo competentemente contestado y satisfecho a todo, acordé aprovarle como le apruevo, con dictamen del dicho asesor ${ }^{7}$.

El "punto de actuación" señalado demuestra la importancia que se concedía a la "habilidad" basada en la práctica de la elaboración de distintos tipos de documentos que normalmente adquirían similares estructuras diplomáticas a las que empleaban los escribanos castellanos. La experiencia de los aspirantes al oficio era una cualidad de mucho peso ante los miembros del cabildo. La experiencia demostrada como oficial de pluma durante tres años en la misma ciudad de Cali y las cualidades reconocidas por sus cabildantes en la persona de José Vernaza (inteligencia, buena reputación, obediencia y sigilo) hacen, en agosto de 1750, innecesaria la realización del examen para ser escribano de cabildo ${ }^{8}$.

Más que el examen, que en la mayoría de las veces, cuando lo había, venía a suponer un mero trámite sin obstáculos, además de que se realizaba después de haber ya obtenido el título y de presentarse ante el cabildo; la experiencia y, al parecer, la confianza en el candidato, quien generalmente se había desempeñado como auxiliar de pluma en la misma escribanía o, como la propia documentación dice refiriéndose a José Vernaza, como "oficial mayor de este archivo", eran las dos cualidades que más pesaban a la hora de aprobar y nombrar al nuevo escribano? ${ }^{9}$

públicos (Primera edición, Granada, 1652), la conocida obra de Pedro Melgarejo Manrique de Lara, con la que contaban, como veremos, los escribanos numerarios de las ciudades de Cartago y Popayán, Juan Andrés Sandoval y Mariano Bueno, respectivamente, dedicaba también un apartado al desarrollo del examen. Miguel Ángel Extremera Extremera, El notariado de la España Moderna. Los escribanos públicos de Córdoba (siglos XVI-XIX) (Madrid: Calambur, 2009), 71.

7 Archivo Histórico de Cali (AHC), T. 31, f. 232r.

8 AHC, T. 18, f. 239 v.

9 Rubio, Los escribanos de la Villa, 113-114. Sobre los aspectos que aquí se tratan, véase completo su capítulo 4. "Habilidad y examen», pp. 96-114. 
A pesar de su responsabilidad e influencia, el oficio fue considerado más como una técnica artesana que como una ciencia elaborada y de complejo aprendizaje, de ahí que la posibilidad de aprenderlo sin acudir a instituciones que lo enseñaran, era una práctica bien considerada. Tampoco en el Nuevo Reino de Granada hubo un Colegio de Escribanos, como sí hubo en Nueva España cofradías de escribanos desde el siglo XVI, llegándose a fundar en 1792, a semejanza del establecido en Madrid, el Real Colegio de Escribanos ${ }^{10}$.

El saber notarial se ocupaba de dar respuestas a casos concretos a través de instructivos de fácil lectura y comprensión. Frente a los letrados (abogados, relatores, oidores), que sí necesitaban aprender una teoría del derecho, para interpretar y valorar sus preceptos, los escribanos eran tratados como simples ejecutores de un conocimiento funcional, aunque de hecho a ambos se les exigiese unos saberes similares. En una sociedad altamente jerarquizada, esta apreciación hacía a unos oficios más nobles que otros, aunque ambos dependían de lo aprendido y asimilado en el trabajo ${ }^{11}$. Pero la práctica diaria de los escribanos no era solo una forma de aprendizaje. Fue reconocida como una fuente de creación de normas capaz de crear derecho, bien por falta de preceptos legales, bien por ir en contravención de ellos ${ }^{12}$.

Aunque bajo el término "letrado" se denominaba tanto a titulados universitarios como a otros hombres "de letras" que podían haber pasado o no por la Universidad, tales

10 Jorge Luján Muñoz, «La literatura notarial en España e Hispanoamérica, 15001820», Anuario de Estudios Americanos, no 38 (1981): 115-116. Adscrita al Colegio se abrió una academia a la cual, por un tiempo de seis meses, debía asistir el futuro escribano. Sin embargo, ello no implicó la eliminación de poder hacer prácticas ante los escribanos.

11 Comprobada la necesidad por parte de la Corona de contar en los pleitos americanos con letrados para su asesoramiento, su número llegó a ser elevado y la burocracia real necesitaba de funcionarios asesores expertos en Derecho. Éstos gozaron de una alta consideración social y la profesión del letrado ofrecía posibilidades de promoción en el escalafón administrativo. Miguel Luque Talaván, Un universo de opiniones. La literatura jurídica indiana (Madrid: Consejo Superior de Investigaciones Científicas. Instituto de Historia, 2003), 153-154.

12 Tamar Herzog, Mediación, archivos y ejercicio, 33-37. 
como escribanos municipales $\mathrm{u}$ otros oficiales ${ }^{13}$, la diferencia entre "letrados" (con conocimientos en teoría del derecho) y "escribanos", quedaba subrayada muchas veces en las decisiones de los cabildantes, cuando no sabiendo solucionar cuestiones legales se acordaba consultar sobre al asunto al "asesor letrado Lorenzo Benítez", o "para proceder con el mejor acierto se consultase a un letrado con cuyo parecer resolver lo más oportuno"14. Los letrados americanos solían ser titulados en "ambos derechos", derecho canónico y derecho civil, pero los jueces no letrados, personal sin título universitario donde podían incluirse a los corregidores, alcaldes mayores, alcaldes de la Santa Hermandad y alcaldes ordinarios, con su personal subalterno de escribanos, procuradores y abogados, también participaban en la creación de una cultura jurídica y producían buena parte de la jurisprudencia que constituía el universo legal ${ }^{15}$.

Al letrado Domingo Ortiz, Procurador del Número de la Real Audiencia, en 1777, como apoderado del escribano Juan José Lotero en el juicio que lo enfrentó a Ignacio Mejía, Oficial Real de Medellín, lo encontramos utilizando para exponer argumentos a su favor, la obra del jurista limense Gaspar de Escalona y Agüero, Gazophilatium Regium Peruvicum ${ }^{16}$.

Los inventarios post mortem, realizados en la ciudad de Popayán en 1782 a José Ignacio Paredo (Teniente Auditor de Guerra en la ciudad de Popayán) ${ }^{17}$; y en la ciudad de Cartago,

13 A. Carlos Merchán Fernández, Gobierno municipal y administración local en la España del Antiguo Régimen (Madrid: Tecnos, 1988), 170.

14 Archivo Histórico de Medellín (AHM), T. 38, f. 18v. y T. 84, f. 141v. Después de asentado el proceso conquistador, los letrados actuaron como asesores de los gobernantes y de los cabildos para resolver las cuestiones de gobierno más complicadas. Estos asesoramientos alcanzaron más importancia aún en el siglo XVIII, cuando se estableció el dictamen letrado obligatorio en las causas civiles y criminales que resolvían los alcaldes (Víctor Tau Anzoátegui, y Eduardo Martiré, Manual de Historia de las instituciones argentinas (Buenos Aires: Macchi, [1975]), 109; citado en Luque Talaván, Un universo de opiniones, 154.

15 Tamar Herzog, «Sobre la cultura jurídica en la América colonial (siglos XVIXVIII)», Anuario de Historia del Derecho español, no 65 (1995): 903-911.

16 AHM, T. 24, f. 184r.-228v.

17 Archivo Central del Cauca (ACC), Popayán - Colombia, Colonia, JIII-20 su., 10581. 
en 1792, a Miguel de Escobar Ospina (Abogado de las Reales Audiencias de Quito y Santa Fe) ${ }^{18}$, reflejan en conjunto, como abogados y juristas que fueron, un alto porcentaje de libros dedicados al derecho, muy por encima del resto de materias como la religión, las humanidades o las ciencias. Ambas bibliotecas son voluminosas y entre los libros de Paredo, como muestra, además de la Recopilación de las Leyes de Indias o las Políticas de Bobadilla y Solórzano, podemos encontrar las Alegaciones fiscales y Decisiones de Granada, de Juan Bautista de Larrea; la Opera jurídica, sive Rerum Quatidianorum, de Juan Yáñez Parladorio, la obra jurídica de Antonio Fernández de Otero; el De iustitia et iure de Luis de Molina; la Colección general de ordenanzas militares, sus innovaciones y aditamientos, de José Antonio Portugués; las Vacantes de Indias, de José Álvarez de Abreu; los Commentarii Juris Civilis in Hispaniae Regias Constitutiones, de Alphonso de Azevedo; o las Siete Partidas editadas y comentadas por Gregorio López Tovar. Todos ellos eran libros técnicos del Derecho y su teoría, propios para letrados especialistas, que generalmente no encontramos entre los escribanos.

La formación de los escribanos, más que académica, fue eminentemente práctica, supliendo esa falta con la lectura de libros generales de Derecho y otros más funcionales sobre aspectos técnicos de distintos negocios jurídicos y el arte notarial. Manuales prácticos que incluían formularios documentales con sus respectivas explicaciones. Manuales al uso español generalmente escritos por escribanos que en el ejercicio de su profesión, a través de su experiencia intentaban facilitar el desarrollo de determinadas tareas. El arte del oficio se adquiría tanto con la preparación práctica, inicialmente ejercida por los escribanos que pasaron a Indias, como con la consulta de distintos manuales o formularios. Así relata su experiencia en el oficio Pedro Pérez Landero Otáñez, escribano en la ciudad de Lima, que escribió la obra Práctica de visitas y residencias (Nápoles, 1696):

18 Archivo Histórico de Cartago (AHCar), J/M/24-2. 
[...] aunque quando comencé a execitarle me parecía que con el estudio de Theórica, y Practica, me hallaba abil, para actuar en cualquier negocio; (pero), me han ocurrido tantos tan arduos, o extraordinarios (...) que sólo con incansable estudio, y aplicación, y consultando a muchos sujetos muy diestros, y sirviéndome de sus formularios, pude salir con reputación de ellos ${ }^{19}$.

A través de los inventarios post mortem de los escribanos que tratamos, dos apreciaciones, en general, caracterizan sus bibliotecas particulares: la escasa presencia de ejemplares y la alta proporción de ejemplares de carácter práctico, es decir, la cantidad considerable de literatura notarial y de recopilaciones legislativas. Se trata, pues, de bibliotecas de carácter más práctico que profesional. En la Mortuoria de Jacobo Facio Lince, escribano del número de Medellín durante los años de 1772 a 1798, entre los solo cinco títulos que aparecen relacionados, tres tienen que ver con su ejercicio como escribano: el Gobierno Eclesiástico Pacífico, y unión de los dos cuchillos, pontificio y regio, de Gaspar de Villarroel; la Política indiana de Solórzano y la Recopilación de las Leyes de Indias ${ }^{20}$. Obras generales de Derecho entre las cuales, la Recopilación, ampliamente citada por los escribanos en sus actuaciones, era un texto elemental que no faltaba en sus bibliotecas, donde a la vez, como es el caso del escribano del número de la ciudad de Cartago, Mariano Bueno, a quien se le ve ejerciendo como tal a fines del siglo XVIII, aparecían los manuales dedicados al ejercicio diario de los escribanos ${ }^{21}$.

19 Jorge Luján Muñoz, «La literatura jurídica notarial en Hispanoamérica durante la colonia", Anales de la Academia Matritense del Notariado, Tomo XXVIII (1987): 14.

20 Archivo Histórico Judicial de Medellín (AHJM), Mortuoria de Jacobo Facio Lince, 1799, Doc. 3703. Los dos títulos restantes tienen que ver con su devoción religiosa (las «obras del Padre Señeri») y la botánica (el «Dioscorides»). Con el Dioscórides se están refiriendo a la obra del griego Pedacio Dioscórides Anazarbeo (c. 40 - c. 90) titulada De materia medica, un tratado de farmacopea que recoge las virtudes terapéuticas de distintas plantas. El humanista segoviano Andrés Laguna (1511-1559) fue el autor de la traducción al castellano más importante de la obra de Dioscórides con el título de Acerca de la materia medicinal y de los venenos mortíferos. Publicada en Amberes en 1555 conoció diez ediciones desde esa fecha hasta el siglo XVIII.

21 AHCar, J/M/251, Mortuoria de Mariano Bueno, 1808. 
En la clasificación de las bibliotecas propuesta por Víctor Infantes a través de los hallazgos de inventarios de libros durante los siglos XVI y XVII españoles (biblioteca práctica, profesional, patrimonial, y biblioteca museo), en la "biblioteca práctica" el libro aparece como un bien primario y elemental, relacionado con su utilidad práctica básica e inmediata, donde se supone que se trata de libros conservados como uso y utilidad primordial de conocimiento. Esta biblioteca establece una vinculación de pertenencia personal y no excedería de los 10/15 asientos bibliográficos ${ }^{22}$. En la biblioteca de Mariano Bueno, como en la de Facio Lince, también son escasas las obras. De un total de doce títulos, cuatro se refieren a obra religiosa, uno es la Recopilación de las Leyes de Indias y el resto, siete, son manuales para escribanos. Su biblioteca era, por tanto, una adquisición exclusivamente de carácter práctico, útil y ajustada al desempeño de un oficio que quienes ocupaban solían compaginar con otro tipo de actividades remunerativas.

En ella aparecen formularios y textos de literatura notarial como los de Manuel Silvestre Martínez (Librería de jueces, utilísima y universal), Pedro Melgarejo Manrique de Lara (Compendio de contratos públicos), Pedro de Sigüenza (Tratado de cláusulas instrumentales), José Juan y Colón (Instrucción de escribanos), José Febrero Bermúdez (Librería de escribanos, o instrucción jurídica teórico-práctica de principiantes y Los cinco juicios de inventario y partición de bienes, ordinario ejecutivo y de concurso y prelación de acreedores) y Carlos Ros (Cartilla real teórico-práctica, según leyes reales de Castilla, para escribanos) ${ }^{23}$. Obras como las de Melgarejo, Sigüenza y Colón se encuentran también en la librería de Juan Andrés Sandoval y Portocarrero, quien fuera

22 Víctor Infantes, «Las ausencias en los inventarios de libros y de biblioteca», Bulletin Hispanique, $\mathrm{n}^{\circ}$ 1, t. 99 (1997): 282-285.

23 El uso del vocablo «instrucción» en los títulos fue costumbre de la época para «reflejar el contenido de cuestiones prácticas y anotaciones de criterios doctrinales, tal como se seguía en los Tribunales en el sentido de estilo» (Introducción de Antonio Agúndez Fernández a la obra de Juan José Colón, Instrucción de escribanos en orden a lo judicial [Edición facsímil de la sexta edición impresa por Gabriel Ramírez en Madrid, 1769] (Valladolid: Editorial Lex Nova, 1993), 8. 
escribano numerario de la ciudad de Popayán a mitad del siglo XVIII ${ }^{24}$. En su biblioteca se relacionan un total de 23 títulos. Sin aparecer ninguna obra de literatura jurídica, los 20 títulos restantes son obras de historia y literatura religiosa, predominando esta última.

Los manuales que poseía Mariano Bueno fueron obras habituales en las Indias. Las de Melgarejo (edición de Granada, 1652) y la de Sigüenza (Madrid, 1646) son relacionadas dentro de las obras clasificadas en el grupo del arte de la notaría por Javier Malagón-Barceló. Este autor, en La literatura jurídica española del siglo de oro en la Nueva España ${ }^{25}$, presenta una serie de "artes notariales" que figuran en las listas presentadas a la Inquisición de la Nueva España por libreros y particulares entre 1585 y 1694. Todas ellas fueron enviadas a través de la Carrera de Indias, salvo la Política de las escrituras de Yrolo, editada en México:

\begin{tabular}{|c|c|c|}
\hline \multicolumn{3}{|c|}{$\begin{array}{c}\text { Obras especializadas de arte notarial en las listas presentadas a la } \\
\text { Inquisición de la Nueva España } \\
\text { Tabla } 1\end{array}$} \\
\hline Autor y título & Oficio & $\begin{array}{l}\mathrm{N}^{\circ} \text { de listas } \\
\text { y años }\end{array}$ \\
\hline $\begin{array}{l}\text { Argüello, Antonio de. Tratado de } \\
\text { escrituras y contratos públicos con } \\
\text { anotaciones. Madrid, } 1630\end{array}$ & Notario en la ciudad de Toro & $\begin{array}{l}\text { 2: } 1655 \\
\text { 2: } 1660\end{array}$ \\
\hline $\begin{array}{c}\text { Arias, Juan. Práctica eclesiástica } \\
\text { para el uso y ejercicio de notarios } \\
\text { públicos y apostólicos y secretarios } \\
\text { prelados. Madrid, } 1603\end{array}$ & $\begin{array}{l}\text { Nacido en Plasencia, quizá } \\
\text { notario apostólico }\end{array}$ & $\begin{array}{l}\text { 1: } 1655 \\
\text { 2: } 1660\end{array}$ \\
\hline
\end{tabular}

24 ACC, Colonia JI-22 su. 8809. Inventario de bienes de 1766.

25 Javier Malagón-Barceló, La literatura jurídica española del siglo de oro en la Nueva España (México: UNAM, 1959), 65, 73-74 y 78. Esta relación de 17 obras es también referenciada por Jorge Luján Muñoz, Los escribanos en las Indias occidentales (México: UNAM/Instituto de Estudios y Documentos Históricos, A.C., 1982), 75-92. Luego, con ligeros cambios, el mismo autor la repite en "La literatura notarial», pp. 101-116; y «La literatura jurídica notarial», pp. 7-26. Pedro Rueda reproduce también el esquema con solo 14 obras, las que aparecen en el apartado «XII. De arte notaria Specialitater» del texto de Malagón-Barceló, pp. 73-74 (Pedro Rueda, «Escrituras de navegación a las Indias: El Estilo Nuevo (1645) de Tomás de Palomares», en El nervio de la República. El oficio de escribano en el Siglo de Oro, ed. por Enrique Villalba y Emilio Torné (Madrid: Calambur, 2010), 421-444. 


\begin{tabular}{|c|c|c|}
\hline \multicolumn{3}{|c|}{$\begin{array}{c}\text { Obras especializadas de arte notarial en las listas presentadas a la } \\
\text { Inquisición de la Nueva España } \\
\text { Tabla } 1\end{array}$} \\
\hline Autor y título & Oficio & $\begin{array}{l}\mathrm{N}^{\circ} \text { de listas } \\
\text { y años }\end{array}$ \\
\hline $\begin{array}{l}\text { Díaz de Valdepeñas, Fernando. } \\
\text { Suma de notas copiosas según el } \\
\text { estilo y uso destos reinos. Toledo, } \\
1546\end{array}$ & $\begin{array}{|llr|}\text { Escribano } & \text { de } & \text { causas } \\
\text { criminales } & \text { de la } & \text { Real } \\
\text { Audiencia } & \text { y } & \text { Chancillería de } \\
\text { Granada } & & \\
\end{array}$ & 1: 1585 \\
\hline $\begin{array}{l}\text { Frías Albornoz, Bartolomé. Arte de } \\
\text { los contratos. Valencia, } 1573\end{array}$ & $\begin{array}{l}\text { Nació en Talavera (Toledo). } \\
\text { Doctor y profesor de la } \\
\text { Universidad de la Universidad } \\
\text { de Sevilla. Abogado en } \\
\text { México, doctor y profesor en la } \\
\text { Universidad de México }\end{array}$ & 1: 1659 \\
\hline $\begin{array}{l}\text { Gali, Jerónimo. Opera artis } \\
\text { Notariae theoricam simul } \\
\text { et practicam eruditionem } \\
\text { complectentia. Barcelona, } 1684\end{array}$ & $\begin{array}{l}\text { Nacido en Gerona, asesor del } \\
\text { Batallón de Milán }\end{array}$ & 1: 1690 \\
\hline $\begin{array}{c}\text { García, Francisco. Tratado utilísimo } \\
\text { de todos los contratos cuantos en los } \\
\text { negocios humanos pueden ofrecer. } \\
\text { Valencia, } 1583 \\
\end{array}$ & $\begin{array}{l}\text { Valenciano. Perteneció a la } \\
\text { orden de Santo Domingo, } \\
\text { profesor de Teología en } \\
\text { Tarragona }\end{array}$ & 1: 1655 \\
\hline $\begin{array}{l}\text { González Torneo, Francisco. } \\
\text { Práctica de escribanos. Alcalá, } 1640\end{array}$ & Notario & $\begin{array}{l}: 1660 \\
1: 1690\end{array}$ \\
\hline $\begin{array}{l}\text { González de Villarroel, Diego. } \\
\text { Examen de escribanos. Madrid, } \\
1641\end{array}$ & Escribano real & $\begin{array}{l}\text { 1: } 1655 \\
2: 1660\end{array}$ \\
\hline $\begin{array}{l}\text { Melgarejo y Manrique de Lara, } \\
\text { Pedro. Compendio de contratos } \\
\text { públicos, autos de particiones y } \\
\text { ejecutivos; con el papel sellado que a } \\
\text { cada cosa pertenece. Granada, } 1652\end{array}$ & $\begin{array}{l}\text { Sevillano. Escribano mayor } \\
\text { del cabildo de la Villa de } \\
\text { Olvera }\end{array}$ & $\begin{array}{l}1: 1655 \\
\text { 3: } 1660\end{array}$ \\
\hline $\begin{array}{c}\text { Molino, Micier Miguel del. } \\
\text { Formularios de actos extrajudiciales } \\
\text { de la sublime arte de la Notaría. } \\
\text { Zaragoza, } 1516\end{array}$ & $\begin{array}{l}\text { Aragonés. Abogado y Jurado } \\
\text { de Capítulo en Zaragoza y } \\
\text { Lugarteniente de la Corte de } \\
\text { Justicia de Aragón. } \\
\end{array}$ & 1: 1659 \\
\hline $\begin{array}{c}\text { Monterroso y Alvarado, Gabriel } \\
\text { de. Práctica civil y criminal e } \\
\text { institución de escribanos. Alcalá, } \\
1571\end{array}$ & $\begin{array}{l}\text { Nació en la ciudad de Toro, } \\
\text { educado en Valladolid }\end{array}$ & $\begin{array}{l}\text { 1: } 1614 \\
1: 1655 \\
\text { 3: } 1660\end{array}$ \\
\hline $\begin{array}{l}\text { Moreno, Miguel. Avisos para los } \\
\text { oficios de provincias y consecuencias } \\
\text { generales para otros. Madrid, } 1631\end{array}$ & $\begin{array}{l}\text { Segoviano. Escribano de la } \\
\text { cura regia, secretarios de } \\
\text { Felipe IV }\end{array}$ & 1: 1660 \\
\hline $\begin{array}{l}\text { Ortiz, Salcedo, Francisco. Curia } \\
\text { eclesiástica para secretarios de } \\
\text { prelados, notarios apostólicos y } \\
\text { ordinarios. Madrid, } 1615\end{array}$ & \begin{tabular}{|l|} 
Madrileño. Notario público, \\
apostólico y real; relator del \\
Consejo de don Fernando de \\
Asturias; arzobispo de Toledo \\
\end{tabular} & $\begin{array}{l}3: 1660 \\
1: 1683\end{array}$ \\
\hline $\begin{array}{l}\text { Palomares, Tomás de. Estilo nuevo } \\
\text { de escrituras públicas. Sevilla, } 1645\end{array}$ & $\begin{array}{l}\text { Sevillano. Escribano del } \\
\text { número de Sevilla }\end{array}$ & 1: 1655 \\
\hline
\end{tabular}




\begin{tabular}{|c|l|c|}
\hline \multicolumn{3}{|c|}{$\begin{array}{c}\text { Obras especializadas de arte notarial en las listas presentadas a la } \\
\text { Inquisición de la Nueva España } \\
\text { Tabla 1 }\end{array}$} \\
\hline Autor y título & \multicolumn{1}{|c|}{ Oficio } & $\begin{array}{c}\mathbf{N}^{\circ} \text { de listas } \\
\text { y años }\end{array}$ \\
\hline $\begin{array}{c}\text { Ribera, Diego de. Primera, segunda } \\
\text { tercera parte de escrituras y } \\
\text { orden de partición y cuenta, } y \\
\text { de residencia judicial, civil y } \\
\text { criminal...Madrid, 1617 }\end{array}$ & $\begin{array}{l}\text { Nació en Ronda (Málaga). } \\
\text { Notario }\end{array}$ & $\begin{array}{l}1: 1604 \\
2: 1614 \\
1: 1655 \\
1: 1660\end{array}$ \\
\hline $\begin{array}{c}\text { Sigüenza, Pedro de. Tratado de } \\
\text { cláusulas instrumentales, útily y } \\
\text { necesario para jueces y escribanos. } \\
\text { Madrid, 1646 }\end{array}$ & $\begin{array}{l}\text { Nació en Ajofrin (Toledo). } \\
\text { Ybogado en ejercicio de }\end{array}$ & $2: 1660$ \\
$1: 1683$ \\
\hline $\begin{array}{c}\text { Yrolo Calar, Nicolás de. Primera } \\
\text { parte de la política de las escrituras. } \\
\text { México, 1605 }\end{array}$ & $\begin{array}{l}\text { Gaditano. Escribano de las } \\
\text { ciudades de Cádiz y México }\end{array}$ & $\begin{array}{l}2: 1655 \\
1: 1660\end{array}$ \\
\hline
\end{tabular}

Tabla 1. Basada en Javier Malagón-Barceló, La literatura jurídica española del siglo de oro en la Nueva España (México: UNAM, 1959), p. 65, 73-74 y 78.

Para nuestro marco neogranadino, escasamente estudiado en lo que respecta a la circulación y posesión de "artes notariales" entre los escribanos de sus muy diversas escribanías, conviene centrarnos al menos en las obras cuya pertenencia ha sido comprobada ${ }^{26}$. El Compendio de contratos públicos, de Pedro Melgarejo, aparece en Granada, en 1652; y le siguen ediciones en Madrid, 1689; Valencia, 1707; Zaragoza, 1708; Madrid, 1724, 1728; Barcelona, 1757; Madrid, 1764 y 1791. Es la primera obra que añade a los asuntos propiamente notariales la regulación sobre el papel sellado que implanta la pragmática de 1636 . El compendio queda dividido en una

26 José Bono y Huerta, «Los formularios notariales españoles de los siglos XVI, XVII y XVIII», Anales de la Academia Matritense del Notariado I, Tomo XXII, (1978): 287-317. Aquí puede verse con más detalle la estructura de las obras señaladas en la Tabla 1, el año de sus ediciones y reediciones, así como la procedencia de sus autores, todos ellos abogados, notarios o escribanos). Bono divide las obras de la literatura notarial española que asimila en la Edad Media la doctrina del Ars notariae, en tres momentos: el de continuidad de la tradición medieval, que ocupa la primera mitad del siglo XVI; el de integración en el Derecho nacional de cada reino, que va de la segunda mitad del siglo XVI hasta el final del XVII; y el de simplificación y racionalización de la disciplina durante el siglo XVIII. Sobre algunos de los manuales que aparecen en la misma tabla, véase también Reyes Rojas, «La literatura notarial de ida y vuelta. Los primeros formularios notariales en América», en El nervio de la República. el oficio de escribano en el siglo de Oro, ed. por Enrique Villalba y Emilio Torné (Madrid: Calambur, 2010), 401-420. 
introducción y cuatro libros. En la introducción se hace un resumen de las principales normas notariales al estilo de las antiguas "Introducciones de escrivanos". El primer libro trata de "contratos y escrituras públicas" con modelos incluso de testamentos y unas "cláusulas universales" de renuncias, sumisiones, juramento, etc. El segundo trata de las fórmulas de "tutela" y "partición". El tercero sobre juicios ejecutivos, con formularios de "vía ejecutiva" y de resoluciones y autos judiciales. El cuarto trata del "juicio de residencia", con cuestionarios y fórmulas. Las citas legales y algunas notas aclaratorias se distribuyen en los márgenes del texto y a la mayoría de las fórmulas le precede una explicación teórica.

El Tratado de cláusulas instrumentales, útil y necesario para jueces y escribanos, de Pedro de Sigüenza, aparece en Madrid, en 1627; y le siguen ediciones en la misma ciudad en los años 1646, 1663 y 1673; Barcelona, 1705; y de nuevo en Madrid, 1720, 1754 y 1767. Dividido en dos tomos, el primero trata las cláusulas instrumentales para documentos de negocios jurídicos inter vivos, y el segundo, para los testamentos. Sin prescindir de la cita erudita de autores, hay contacto directo con las fuentes legales castellanas. La obra fue indispensable para la práctica notarial con amplia gama de modelos originales, que no copiaban los tratados clausulares clásicos. Por su especialización basada en el derecho castellano y por no redactarse en latín, no logró integrarse en la literatura europea, a diferencia de las Prácticas Quaestiones, de Diego de Covarrubias y el Tractatus de iuramento confirmatorio, de Juan Gutiérrez ${ }^{27}$.

Las obras de Diego de Ribera, Gabriel de Monterroso, Antonio de Argüello, Tomás de Palomares, Pedro Melgarejo, Pedro Sigüenza, Diego González de Villarroel y la Política de escrituras de Nicolás de Yrolo, cuya primera edición de la "Primer parte" aparece en México, en 1603, se utilizaron

27 Las obras de Melgarejo y Sigüenza las encontramos también en las bibliotecas de los jesuitas. José del Rey Fajardo, La biblioteca colonial de la Universidad Javeriana de Bogotá (Caracas: Miguel Ángel García e hijo, 2001), 705 y 731. 
frecuentemente en Indias $^{28}$. El periodo de actuación de nuestros escribanos se centra en el siglo XVIII y, por lo general, las ediciones de los manuales que emplearon son de este siglo. Sus dos primeros tercios estuvieron marcados por una improductividad en el campo de la literatura notarial debido a que tanto en Castilla como en Aragón, Cataluña y Valencia, se inició una lenta transformación en la redacción del documento público, tendiéndose a la brevedad y la claridad en la redacción, lo que hizo menos necesarios los formularios antiguos, pues era deficiente su parte doctrinal y anticuados sus modelos. Por otro lado, no era fácil renovar las obras antiguas y algunas de ellas se siguieron utilizando. Así, en Castilla los viejos tratados como los de Ribera, Monterroso; o los de Bartolomé Carvajal (Instrucción y memorial para escrivanos y jueces executores, Grandada, 1580) y Tomás de Palomares (Estilo nuevo de escrituras publicas, Sevilla, 1645) habían quedado olvidados. Solo de la obra Diego González de Villarroel (Examen de escrivanos), patrocinada por el Consejo Real, se hace una edición en 1728. En cambio, perduraron algunos exitosos manuales prácticos como el Compendio de Melgarejo, que no cesó de reeditarse hasta 1791; y las obras de Ortiz de Salcedo y de Sigüenza, que llegaron a editarse hasta más allá de mediados del siglo XVIII.

En Cataluña, la obra de Jerónimo Galí y la de José Comes, compuesta en 1694 (Viridarium artis notariatus, reeditada en dos volúmenes en Gerona, 1704 y 1706), estuvieron durante todo el siglo XVIII en plena vigencia, pues fueron obras modernas y de calidad. Solo algunas obras como la Cartilla real de Carlos Ros, la Instrucción de escrivanos (1736; $2^{\mathrm{a}}$ ed., Madrid, 1761) de José Juan y Colom; o el Manual de testar, dividir y partir (1739; $2^{\mathrm{a}}$ ed. Madrid, 1768), de José Barní, aparecen entonces en Castilla.

\footnotetext{
28 De la obra de Yrolo hubo dos ediciones en la ciudad de México, la de 1603 y la de 1605, no habiéndose impreso una segunda parte. Marca pautas de formulación de escrituras intentando reformar las expresiones arcaicas con diversas adiciones para «casos y asuntos extraordinarios» (Luján Muñoz, La literatura jurídica, 18). Sobre Yrolo véase Julián Calvo, «El primer formulario jurídico publicado en la Nueva España: La política de Escrituras de Nicolás de Irolo (1605)», Revista de la Facultad de Derecho de México, no I, 3-4 (1951): 41-102.
} 
La Cartilla real teórico-práctica del valenciano, notario y escribano público apostólico y real, Carlos Ros (1703-1773), instauró la nueva modalidad de la "Cartilla". Ros cuenta con varias obras y la primera de ellas la compuso en Pamplona en 1738, originalmente denominada Norte y examen de escrivanos públicos, cuyo original vendió a un clérigo, quien la editó con el título de Cartilla real teórico-práctica, según leyes reales de Castilla, para escribanos, bajo el nombre ficticio de Diego Bustos y Lisares. Fue reimpresa en Valencia, Barcelona y Madrid, conociéndose en esta última ciudad una impresión de 1816. Ante la gran difusión obtenida por la Cartilla real, en 1762 publicó en Valencia una "Cartilla real enmendada y adicionada" bajo su propio nombre. Se ajustó a las leyes castellanas y su parte teórica se confeccionó a base de respuestas con modelos intercalados entre ellas en materia de contratos y testamentos, con ciertas referencias a actuaciones judiciales.

La Librería de escribanos y Los cinco juicio de inventario, del notario madrileño José Febrero, aparecen en Madrid, en 1769 (3 vols.) y 1772 (4 vols.) respectivamente. La Librería de escribanos fue objeto de múltiples ediciones que ampliaron los volúmenes con sucesivas reformas, ampliaciones y renovaciones que rebasaron la primera mitad del siglo XIX y estuvo vigente, gracias a sus últimas ediciones, hasta la promulgación de la Ley del Notariado española de 1862. Tuvo mucha difusión en Indias, incluso después de la Independencia, y al iniciarse el siglo XIX se convierte en el tratado clásico castellano, utilizado en el campo notarial y en el judicial. Representa una enciclopedia del derecho privado castellano y un formulario completo de escrituras y de actuaciones judiciales.

El Compendio de Melgarejo y la Cartilla real de escribanos de Carlos Ros, son libros con los que contaba el "Escribano Publico, de Cavildo y Gobernación" de la ciudad de Popayán, Joaquín Sánchez de la Flor. Ejerció el cargo durante 30 años, desde 1746 a 1776; fue hijo del peninsular Lucas Sánchez de la Flor, mercader de Popayán, y de la payanesa Jacinta de Huegonaga Salazar. Se emparentó con las élites sociales de la ciudad al casar tres veces: la primera con 
Nicolasa Benítez de Astaíza, la segunda con Paula de Lucena y Velasco, y la tercera con Juana de Ayerbe y Lemos ${ }^{29}$. De su segundo matrimonio nació, entre otros hijos, Juana Francisca Sánchez, quien fuera mujer del también "Escribano Publico, de Cavildo y Gobernación", Antonio de Zervera, natural de la ciudad de Pamplona (Navarra, España) y en quien su suegro había renunciado el oficio.

La posición social de Joaquín Sánchez de la Flor hace posible que su biblioteca contara con un total de 95 títulos; una biblioteca patrimonial que concedía prestigio social y era símbolo de bienestar económico, de la decencia y el honor con que en la sociedad de la época, conforme a su estado y condición, debía sustentar, invirtiendo en gastos destinados a la ostentación, quien poseía la posibilidad de establecer una extensa red clientelar ejerciendo varios tipos de escribanía a la vez. Dedicado también a la compra y venta de solares, sus bienes eran cuantiosos y un índice de su riqueza es la hacienda con capilla que poseía en Chiribío, donde, además de esclavos, contaba con un considerable número de cabezas de ganado equino, ovino y vacuno ${ }^{30}$.

Abundan en la biblioteca de Sánchez de la Flor los temas humanísticos (literatura e historia sobre todo) y los temas religiosos. A diferencia de otras librerías de escribanos, donde la literatura jurídica es escasa, en esta, entre los títulos que aparecen, algunos de ellos pudieron ser válidos para su ejercicio: las Ordenanzas Reales de Castilla (el Ordenamiento de Montalvo), un repertorio en dos tomos de las "Leyes de Castilla", las "adiciones" de José Manuel Domínguez a la Curia Filípica de Bolaños, las "Pandectas" de Justiniano, el De ratiociniis administratorum de Francisco Muñoz de

29 ACC, 10636, Colonia, J II-22 su, Causa mortuoria, 1787-1790. Sobre los orígenes sociales de sus esposas, véase Gustavo Arboleda Restrepo, Diccionario biográfico y genealógico del antiguo Departamento del Cauca. (Cali: Centro de Estudios Históricos y Sociales «Santiago de Cali»/Gerencia Cultural de la Gobernación del Valle, 1996).

30 ACC, 10636, Colonia, J II-22 su, Causa mortuoria, 1787-1790, ff. 42r.-45r. (1788); y ACC, Notaría 1, T. 1, ff. 3r.-5v. (1749). Sobre los escribanos que se introducían en el ámbito de las costumbres y convenciones de la clase aristocrática a través de la riqueza, véase Rubio, Los escribanos de la Villa, 128-131. 
Escobar, el De jure ecclesiastico universo de Agustín Barbosa, el "Comunes contra comunes" de Jerónimo Cevallos, y la Suma de leyes penales de Francisco de la Pradilla. Junto a ellos, se encuentran obras de utilidad práctica como la Curia eclesiástica para secretarios de prelados, jueces eclesiásticos, notarios apostólicos...de Francisco Ortiz de Salcedo; y la "Curia Filípica" de Juan Hevia Bolaños, un texto este último que no podía faltar en Indias. José Torre Revello, junto a manuales dedicados al "estilo de cartas", o tratados de escribanos como el "Palomares Escrituras", el "Melgarejo de Escrituras", y el "Argüellos de Escrituras", lo registra en varios listados de la Carrera de Indias ${ }^{31}$.

Además de estas obras de teoría y práctica jurídica y además de los populares manuales de Melgarejo y Carlos Ros, Joaquín Sánchez de la Flor poseía el "Ripia de testamentos" y el "Martínez o Librería de jueces". Con el nombre de "Ripia de testamentos" era conocida la Práctica de testamentos y modos de suceder (1718) del contador real Juan de la Ripia. Manuel Silvestre Martínez, quien fuera abogado de los reales consejos, fiscal en la Real Audiencia de Santa Fe del Perú y Oidor subdelegado en Guadalaxara de Nueva España, fue el autor de la Librería de jueces, utilísima y universal, una obra que salió por primera vez en 1763 , se reimprimió numerosas veces e incluía formularios de juicios prácticos válidos para ministros de justicia y escribanos públicos.

\section{Conclusiones}

Los aspirantes a la titularidad del cargo adquirían sus conocimientos a través de la práctica laboral que realizaban bajo la dirección de quien ya dominaba el oficio. La falta de preparación académica y jurídica, y el aprendizaje empírico,

31 José Torre Revello, El libro, la imprenta y el periodismo en América durante la dominación española (México DF: Universidad Nacional Autónoma de México, 1991), CVI-CXIII. Sobre el Estilo nuevo de escrituras de Tomás de Palomares, véase Rueda, «Escrituras de navegación», 421-444. La Curia Filípica aparece también en la librería de José Beltrán, presbítero de Popayán (ACC, 9631, Colonia Eclesiástico, EI-17J, 1776, f. 24v.) 
fueron la causa de la utilización de formularios y obras de derecho para la redacción de los instrumentos, cuyas fórmulas también podían copiarse de las escrituras formalizadas por otros escribanos.

Entre las bibliotecas de los escribanos investigados podemos constatar la presencia de ocho tratados o formularios distintos de uso práctico. Siete de ellos los posee un solo escribano, Mariano Bueno, de cuyos títulos, el Melgarejo, el Sigüenza y el Colón, los posee también Juan Andrés Sandoval Portocarrero; y la Cartilla de Carlos Ros, la posee Joaquín Sánchez de la Flor, que además cuenta con dos distintos manuales, la Ripia de testamentos, y el Martínez o la Librería de jueces. La desproporción parece indicar que no era frecuente contar con tal cantidad de tratados o compendios como con los que contaba Mariano Bueno.

La ausencia de obras de derecho entre las pertenencias de Juan Andrés Sandoval y los títulos sobre esta materia encontrados a Jacobo Facio Lince y Mariano Bueno, indican que lo normal fue que los escribanos utilizaran obras de carácter general para la consulta de aspectos legislativos o jurídicos, obras como la Recopilación de las Leyes de Indias, que poseen los dos últimos escribanos, obras como las de Solórzano y Gaspar Villarroel, que posee Facio Lince, u obras como los repertorios de leyes castellanas o la Curia eclesiástica de Ortiz de Salcedo y la Curia Filípica de Hevia Bolaños, que pertenecieron a Joaquín Sánchez de la Flor.

En la ciudad de Popayán, el nombramiento de escribano adjudicándole la posibilidad de ejercer varios tipos de escribanías al mismo tiempo, pudo ser causa por la que escribanos como Joaquín Sánchez de la Flor contaran con un mayor número de obras jurídicas, aunque el caso de este escribano, como vimos, es excepcional y, por otro lado, Popayán, frente a la Villa de Medellín, en nuestro caso, fue un centro colonial de mayor relevancia geopolítica y administrativa para la Corona, y por tanto también fue mayor allí el comercio y la circulación del libro, que ampliaban las posibilidades de compra. 


\begin{tabular}{|c|c|c|c|}
\hline \multicolumn{4}{|c|}{$\begin{array}{c}\text { Literatura jurídica y tratados de escribanos } \\
\text { Nuevo Reino de Granada, siglo XVIII } \\
\text { Tabla } 2\end{array}$} \\
\hline $\begin{array}{l}\text { Nombre y } \\
\text { periodo de } \\
\text { ejercicio }\end{array}$ & $\begin{array}{c}\text { Escribanía } \\
\text { y ciudad }\end{array}$ & Obra jurídica & $\begin{array}{l}\text { Tratados de } \\
\text { escribanos }\end{array}$ \\
\hline $\begin{array}{l}\text { Jacobo } \\
\text { Facio Lince, } \\
1772-1798\end{array}$ & $\begin{array}{l}\text { Escribano } \\
\text { numerario, } \\
\text { Medelllín }\end{array}$ & $\begin{array}{l}\text { 1. Gaspar Villarroel, Gobierno } \\
\text { Eclesiástico Pacífico... } \\
\text { 2. Solórzano, Política indiana. } \\
\text { 3. Recopilación de las Leyes de } \\
\text { Indias. }\end{array}$ & \\
\hline $\begin{array}{l}\text { Marian } \\
\text { Bueno, } \\
\text { fines del } \\
\text { siglo XVIII }\end{array}$ & $\begin{array}{l}\text { Escribano } \\
\text { numerario, } \\
\text { Cartago }\end{array}$ & $\begin{array}{l}\text { 1. Recopilación de las Leyes de } \\
\text { Indias }\end{array}$ & $\begin{array}{l}\text { 1. Manuel Silvestre } \\
\text { Martínez, Librería } \\
\text { de jueces. } \\
\text { 2. Melgarejo Manrique } \\
\text { de Lara, Compendio } \\
\text { de contratos. } \\
\text { 3. Pedro de Sigüenza, } \\
\text { Tratado de cláusu- } \\
\text { las. } \\
\text { 4. José Juan y Colón, } \\
\text { Instrucción de escri- } \\
\text { banos. } \\
\text { 5. José Febrero, Libre- } \\
\text { ría de escribanos. } \\
\text { 6. José Febrero, Los } \\
\text { cinco juicios de in- } \\
\text { ventario. } \\
\text { 7. Carlos Ros, Cartilla } \\
\text { real teórico-práctica. }\end{array}$ \\
\hline $\begin{array}{c}\text { Juan An- } \\
\text { drés Sando- } \\
\text { val y Por- } \\
\text { tocarrero, } \\
\text { mitad del } \\
\text { siglo XVIII } \\
\end{array}$ & $\begin{array}{l}\text { Escribano } \\
\text { numerario, } \\
\text { Popayán }\end{array}$ & & $\begin{array}{l}\text { 1. Melgarejo, Compen- } \\
\text { dio de contratos. } \\
\text { 2. Sigüenza, Tratado } \\
\text { de cláusulas. } \\
\text { 3. Colón, Instrucción } \\
\text { de escribanos. }\end{array}$ \\
\hline $\begin{array}{l}\text { Joaquín } \\
\text { Sánchez } \\
\text { de la Flor, } \\
\text { 1746-1776 }\end{array}$ & $\begin{array}{l}\text { Escribano } \\
\text { Público, de } \\
\text { Cabildo y } \\
\text { Goberna- } \\
\text { ción, Popa- } \\
\text { yán }\end{array}$ & $\begin{array}{l}\text { 1. Ordenamiento de Montalvo } \\
\text { 2. Repertorio de Leyes de Castilla } \\
\text { 3. Adiciones de José Manuel } \\
\text { Domínguez a la Curia Filipica } \\
\text { 4. Pandectas, Justiniano } \\
\text { 5. De ratiociniis administrato- } \\
\text { rum, Escobar } \\
\text { 6. De jure ecclesiástico, Agustín } \\
\text { Barbosa } \\
\text { 7. Comunes contra comunes, } \\
\text { Cevallos } \\
\text { 8. Suma de leyes penales, } \\
\text { Francisco de la Pradilla } \\
\text { 9. Curia eclesiástica, Francisco } \\
\text { Ortiz de Salcedo } \\
\text { 10. Curia Filipica, Juan Hevia } \\
\text { Bolaños }\end{array}$ & $\begin{array}{l}\text { 1. Melgarejo, Compen- } \\
\text { dio de contratos } \\
\text { 2. Carlos Ros, Cartilla } \\
\text { real } \\
\text { 3. Juan de la Ripia, } \\
\text { Práctica de testa- } \\
\text { mentos y modos de } \\
\text { suceder } \\
\text { 4. Manuel Silvestre } \\
\text { Martínez, Librería } \\
\text { de jueces, utilísima y } \\
\text { universal }\end{array}$ \\
\hline
\end{tabular}

Tabla 2: Elaboración propia. 
El archivo de los cabildos de las ciudades de Medellín, Popayán y Cartago demuestran que en su ejercicio burocrático se continuó preferiblemente repitiendo lo que se hacía desde antaño, seguir las fórmulas establecidas en los distintos tipos documentales (actas, correspondencia, escrituras, testamentos, etc.) que se encontraban en los libros de registros documentales o en los protocolos de sus antecesores. El archivo, de esta manera, se convirtió en ejemplo de variadas y múltiples actuaciones que podían imitarse o cambiarse a conveniencia. La continuidad en las prácticas de redacción siguiendo, por lo general, las enseñanzas del escribano saliente, y la dependencia de modelos acumulados en el propio archivo del Cabildo, hicieron que las fórmulas y estructuras clásicas de los documentos permanecieran durante todo el periodo colonial prácticamente iguales.

Pero al lado de una actividad que en la mayoría de los casos escriturarios pudiera reducirse a un quehacer formulista y rutinario, a juzgar por las coincidencias en los hallazgos de literatura jurídica y tratados notariales entre las pertenencias de los escribanos, estas obras cumplirían con una función auxiliar cuyas fórmulas podrían consultarse con carácter de novedad para poder ser puestas en práctica o con carácter de reforzamiento a las ya formalizadas en otros registros documentales.

\section{Fuentes documentales}

Archivo Central del Cauca (ACC), Popayán - Colombia. Archivo Histórico de Cali (AHC), Cali - Colombia Archivo Histórico de Cartago (AHCar), Cartago - Colombia Archivo Histórico de Medellín (AHM), Medellín - Colombia Archivo Histórico Judicial de Medellín (AHJM), Medellín - Colombia 


\section{Bibliografía}

Agúndez Fernández, Antonio. Introducción a Instrucción de escribanos en orden a lo judicial [Edición facsímil de la sexta edición impresa por Gabriel Ramírez en Madrid, 1769], de Juan José Colón. Valladolid: Editorial Lex Nova, 1993.

Arboleda Restrepo, Gustavo. Diccionario biográfico y genealógico del antiguo Departamento del Cauca. Cali: Centro de Estudios Históricos y Sociales «Santiago de Cali» / Gerencia Cultural de la Gobernación del Valle, 1996.

Bono y Huerta, José. «Los formularios notariales españoles de los siglos XVI, XVII y XVIII». Anales de la Academia Matritense del Notariado I, Tomo XXII. (1978): 287-318.

Burns, Kathryn. Into the Archive: Writing and Power in Colonial Peru. Durham: Dake University Press, 2010.

Calvo, Julián. «El primer formulario jurídico publicado en la Nueva España: La política de Escrituras de Nicolás de Irolo (1605)». Revista de la Facultad de Derecho de México, n I, 3-4 (1951): 41-102.

Extremera Extremera, Miguel Ángel. El notariado de la España Moderna. Los escribanos públicos de Córdoba (siglos XVIXIX). Madrid: Calambur, 2009.

Guajardo-Fajardo Carmona, María de los Ángeles. Escribanos en Indias durante la primera mitad del siglo XVI. [Tomos I]. Madrid: Colegios Notariales de España, 1995.

Herzog, Tamar. «Sobre la cultura jurídica en la América colonial (siglos XVI-XVIII)». Anuario de Historia del Derecho español, nº 65 (1995): 903-911.

Mediación, archivos y ejercicio. Los escribanos de Quito (siglo XVII). Frankfurt: Vittorio Klostermann, 1996.

Icaza Dufour, Francisco. "Nicolás de Yrolo Calar y su obra». Cuadernos del Instituto de Investigaciones Jurídicas. Literatura histórico-jurídica mexicana, nº 4 (1987): 19-30. 
Infantes, Víctor. "Las ausencias en los inventarios de libros y de biblioteca». Bulletin Hispanique, nº 1, t. 99 (1997): 282-285.

Luján Muñoz, Jorge. "La literatura notarial en España e Hispanoamérica, 1500-1820». Anuario de Estudios Americanos, $\mathrm{n}^{\circ}$ 38, (1981): 115-116.

Los escribanos en las Indias occidentales. México DF: UNAM/Instituto de Estudios y Documentos Históricos, A.C., [1964] 1982.

«La literatura jurídica notarial en Hispanoamérica durante la colonia». En Anales de la Academia Matritense del Notariado, Tomo XXVIII (1987): 7-26.

Luque Talaván, Miguel. Un universo de opiniones. La literatura jurídica indiana. Madrid: Consejo Superior de Investigaciones Científicas. Instituto de Historia, 2003.

Malagón-Barceló, Javier. La literatura jurídica española del siglo de oro en la Nueva España. México: UNAM, 1959.

Merchán Fernández, A. Carlos. Gobierno municipal y administración local en la España del Antiguo Régimen. Madrid: Tecnos, 1988.

Rey Fajardo, José del. La biblioteca colonial de la Universidad Javeriana de Bogotá. Caracas: Miguel Ángel García e hijo, 2001.

Rojas, Reyes. «La literatura notarial de ida y vuelta. Los primeros formularios notariales en América». En El nervio de la República. El oficio de escribano en el Siglo de Oro, editado por Enrique Villalba y Emilio Torné. Madrid: Calambur, 2010. 401-420.

Rubio, Alfonso. Los escribanos de la Villa de Medellín, 1675-1819. La representación de un oficio en la escritura de su archivo. Medellín: Universidad de Antioquia, 2015.

Rueda, Pedro. «Escrituras de navegación a las Indias: El Estilo Nuevo (1645) de Tomás de Palomares». En El nervio de la República. El oficio de escribano en el Siglo de Oro, editado por Enrique Villalba y Emilio Torné. Madrid: Calambur, 2010. 421-444. 
Torre Revello, José. El libro, la imprenta y el periodismo en América durante la dominación española. México DF: Universidad Nacional Autónoma de México, 1991.

\section{Citar este artículo:}

Rubio Hernández, Alfonso. «Los tratados de práctica notarial en las bibliotecas de escribanos neogranadinos del siglo XVIII». Historia Y MEMORIA, n 13 (2016): 19-46. DOI: http://dx.doi. org/10.19053/20275137.5198 